\title{
Balloon Septostomy for Transposition of the Great Arteries
}

\author{
S. P. SINGH, R. ASTLEY, AND F. G. O. BURROWS \\ From the Departments of Cardiology and Radiology, The Children's Hospital, Birmingham, \\ United Birmingham Hospitals and University of Birmingham
}

Transposition of the great arteries is not a rare anomaly in infancy. Campbell and Suzman (1951) found an incidence of over 6 per cent among 400 cases of cyanotic heart disease. Among 138 cases of congenital heart disease under the age of 6 months, Coleman (1965) found that 27 had transposition of the great arteries. The anomaly is characterized by a short life and, with a few exceptions, death occurs in the first 6 months (Keith, Rowe, and Vlad, 1967). In children who live to more than 2 years of age, the correction of the condition by Mustard's technique has been successful (Mustard, 1964). Therefore, early palliative treatment is desirable to keep the child alive long enough for this operation to become possible. In 1950 Blalock and Hanlon introduced the palliative surgical technique of creating an interatrial septal defect for improved mixing of blood. This operation, however, carries a high mortality rate in small, deeply anoxic infants. The risks of thoracotomy, anaesthesia, and post-operative complications are obvious. The closed technique of rupturing the foramen ovale by repeatedly withdrawing a balloontipped Rashkind catheter (Rashkind and Miller, 1966; Watson and Rashkind, 1967), or Fogarty embolectomy catheter (Singh, Astley, and Parsons, 1968), from the left atrium to the right atrium achieves the same purpose as the Blalock Hanlon operation.

\section{SUBJECTS AND METHODS}

From November 1966 to November 1968, 38 infants with transposition of the great arteries were treated by balloon septostomy. One patient with transposition who had a large atrial septal defect and did not require palliative treatment, and four who had additional serious anomalies, such as severe coarctation of the aorta and tricuspid atresia, are not considered in this report. At the time of balloon septostomy the ages of these infants

Received April 10, 1969. varied from a few hours to 3 months. All infants had a moderate to severe degree of cyanosis and with a few exceptions were in severe congestive cardiac failure. The diagnosis was confirmed by cine-angiocardiography from the right cephalic vein. Astrup values invariably showed metabolic acidosis, and this was corrected by giving intravenous sodium bicarbonate before starting the procedure. The right femoral vein was exposed and ligated just below the junction of the saphenous vein. A size 6 Fogarty's embolectomy catheter or a double lumen Rashkind catheter (Fig. 1) was introduced into the femoral vein and passed into the right atrium. The tip was manipulated through the foremen ovale into the left atrium (Fig. 2), with confirmation of its position by screening in the left anterior oblique position and often by entry into a pulmonary vein. As far as possible,

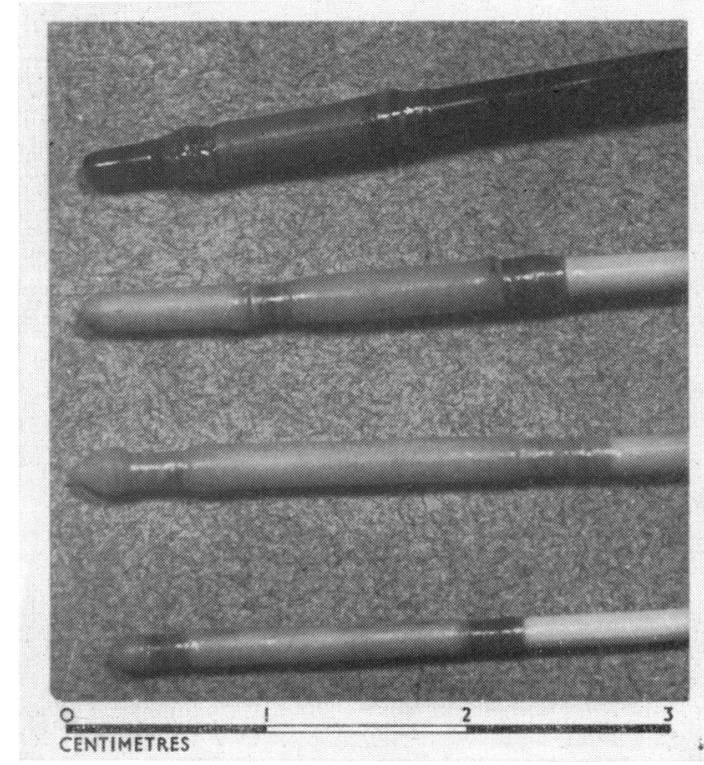

Fig. 1.-The tips (from above downwards) of Rashkind, No. 6 thrombectomy, and Nos. 6 and 5 embolectomy catheters. 
hypertension which is responsible for pulmonary venous congestion and respiratory distress. Improved atrial communication also provides better mixing of blood and produces higher systemic arterial oxygen saturation. However, the mortality of this operation is high, and it has been reported to be as much as 53 per cent in one large series (Cornell et al., 1965).

The results of balloon septostomy in this hospital, as in other medical centres (Rashkind and Miller, 1968; Tynan, 1968), indicate that this closed method is a safer one than the open creation of an artificial atrial septal defect. Only 4 of 38 infants deteriorated and died soon after the procedure.

One of these had previously been resuscitated after multiple cardiac and respiratory arrests and was on a positive pressure ventilator when the procedure was attempted; another had a subarachnoid haemorrhage in addition to his heart defect. In most babies the cyanosis and signs of congestive heart failure improved after the balloon septostomy. The right atrial saturation was measured in 21 cases and it ranged from 15 to 47 per cent before and 57 to 79 per cent after the balloon septostomy. The average rise in the oxygen saturation immediately after the procedure was 26 per cent. We have not measured oxygen saturation at a later stage, but this early rise is comparable to the figure of an approximate 18 per cent rise in the arterial oxygen saturations a few months after the Blalock Hanlon operation that was found by Shaher and Kidd (1966).

Some patients were so improved after the balloon septostomy that they had to stay in hospital for only a few days. In 5 children with a moderateto-large ventricular septal defect and a large pulmonary blood flow the results were not so dramatic. One had required pulmonary artery banding before the balloon septostomy was attempted and later died. One developed severe bronchopneumonia and died 3 weeks later. Another infant with a large ventricular septal defect died 6 weeks later. Pulmonary artery banding was contemplated but he developed severe staphylococcal pneumonia. The two babies who survived required a long stay in hospital and vigorous anticongestive measures.

In most infants with transposition of the great arteries and a sizeable ventricular septal defect there is an excessive pulmonary blood flow because the pulmonary vascular resistance is lower than the systemic resistance. The volume overload of the left ventricle increases the filling pressure in the left atrium, leading to left heart failure. Lack of success of medical treatment and confirmation of a large pulmonary blood flow (as shown most readily by the degree of pulmonary plethora on chest radiography) should indicate the need for pulmonary artery band- ing for such cases. As well as decreasing the pulmonary blood flow and relieving left heart failure, pulmonary banding should prevent development of serious pulmonary vascular changes which have been reported to occur in transposition at a very early age (Mustard, Keon, and Trusler, 1968).

Smaller ventricular septal defects and persistent ductus arteriosus, which are common in transposition, do not appear to be so significant haemodynamically, and do not interfere with the clinical improvement given by septostomy. Of our 24 living patients, 11 had a small ventricular septal defect, 3 with an additional persistent ductus arteriosus; 3 had an isolated persistent ductus arteriosus.

Improvement after septostomy that is only temporary may be due to stretching of the foramen ovale without adequate tearing. In 6 infants after an initial improvement which lasted 1 week to 4 months there was progressive increase in cyanosis and dyspnoea. Repeat arterial oxygen saturation measurement and, in two cases, venous angiocardiography, confirmed the inadequate flow through the interatrial communication. A second septostomy was attempted in these 6 but was satisfactory in only 1 ; the other 5 required a Blalock Hanlon operation.

In 1965 in experimental balloon septostomy on cadavers we failed to obtain satisfactory tears. This was initially attributed to the age of the subjects, who were some months old (Singh et al., 1968). However, our recent experience suggests that a tough, untearable septum may cause failure in some infants who are only a few days old, while on the other hand, it is quite easy to tear the septum in some older children. Indeed, we have performed balloon septostomy with success in a 10-year-old boy (not included in this series). Thus it is not possible to suggest an upper age limit for the procedure.

Twenty-nine infants $(76 \%)$ left the hospital after balloon septostomy (one of these had in addition a Blalock Hanlon operation). Of these, 24 children (63\%) are now attending the follow-up clinic and have been followed from 2 months to 2 years. They show no evidence of cardiac failure and have a mild to moderate degree of cyanosis. One child, age 1 year, has more cyanosis than the others and this is attributable to associated pulmonary stenosis. There were 5 late deaths, and 1 child died four and a half months after balloon septostomy when an additional Blalock Hanlon operation was performed. The cause of sudden death at home in two asymptomatic mildly cyanosed infants was not determined; one of these had a Blalock Hanlon operation. Two of the late deaths occurred in apparently well infants due to thrombosis of the internal 
carotid artery and its branches. Two more infants aged 18 months and 1 year had two episodes of cerebral thrombosis. All these babies were not very cyanosed and did not show evidence of dehydration or secondary polycythaemia. The bursting of the balloon is not uncommon during septostomy. We do not have records of its frequency or whether it actually occurred in these cases but there does exist the possibility that a minute fragment of rubber has led to clot formation and subsequent late embolization.

For minimum disturbance of the patient during septostomy, there is advantage in making the procedure as short as possible. Preliminary investigation can be very brief. A venous or right atrial contrast injection, with viewing on the television monitor of the $x$-ray image intensifier (preferably augmented by video tape recording), is usually sufficient to establish the diagnosis without waiting for processing of the cine-angiocardiogram. Balloon septostomy can follow immediately, without recourse to full catheterization.

The No. 5 and 6 Fogarty embolectomy catheters have acorn tips which are sometimes easier to introduce than the Rashkind No. $6 \frac{1}{2}$ catheters. They are also cheaper but do have the slight disadvantage that they need filling with contrast medium to make them radio-opaque and they do not have a second lumen. The Fogarty thrombectomy catheter has a slightly less satisfactory tip, but it is radio-opaque and its balloon appears stronger. Recently we have used it with up to $5 \mathrm{ml}$. fluid.

Bleeding at the insertion site has occasionally been a problem. Preliminary tying of the femoral vein below the point of incision reduces the hazard should the vein tear. Occasionally we have had trouble with abnormal, tortuous, thin-walled vessels, sometimes bilaterally. Preliminary establishment of a continuous drip and cross-matching of blood is a wise precaution. If blood loss is more than approximately 5 per cent of the blood volume it should be replaced.

During manipulation of the catheter, pressure of its tip against the right atrial wall when attempting to enter the left atrium is apt to slow the heart and perhaps begin a chain of more severe rhythm disturbances. Such pressure is best kept to a minimum; if the catheter persists in an inferior-superior course it can usually be induced to turn backwards into the left atrium by inserting a wire stilette (such as that supplied with a Fogarty catheter), with a slight bend near its tip.

Transient arrhythmias during the pull-back of the balloon from the left atrium to the right atrium are not uncommon, especially if the pull is a slow one. The common arrhythmias seen were first degree heart block, bradycardia, wandering pacemaker, and nodal rhythm. One infant developed atrial fibrillation which responded to intravenous epanutin. Of the 4 early deaths already discussed, 2 had developed complete heart block and one had severe bradycardia. Another moribund child, who previously had several episodes of ventricular fibrillation, had a further attack and died. One child developed a complete heart block which disappeared at the end of the procedure. Similarly, right bundle-branch block in one case was also of short duration. Babies have been known to develop permanent arrhythmias after the Blalock Hanlon operation (Hamilton et al., 1968), but permanent abnormal rhythm has not been reported after balloon septostomy.

During the first few septostomies we measured the pressure in the atria before and after rupturing the septum. Our experience suggested that a rise in the right atrial oxygen saturation indicated that a good tear had been made and that left atrial hypertension had been relieved. Subsequently we used a rise in right atrial saturation as a guide to satisfactory completion of the procedure. The size of the defect that has been created can also be estimated by observing the ease with which a partially filled balloon can be passed in both directions through the septum.

The use of balloon septostomy is not restricted to transposition. We have also used this palliative technique in tricuspid atresia and in total anomalous pulmonary venous drainage. Its use has been recommended for other conditions such as Ebstein's anomaly, mitral atresia, and pulmonary atresia with intact ventricular septum (W. J. Rashkind, 1967, personal communication).

\section{SUMMARY}

The technique and results of Rashkind's procedure of balloon septostomy for creating an atrial septal defect have been reviewed from experience with 38 cases of transposition of the great arteries. Of the 38 infants, 34 survived balloon septostomy. There were 5 more delayed deaths in the hospital and 29 patients $(76 \%)$ left the hospital. There are $24(63 \%)$ long-term survivals. These results show that this method of creating an atrial septal defect is safer than the Blalock Hanlon operation.

We thank Dr. C. G. Parsons for his helpful discussion and criticisms.

\section{REFERENCES}

Blalock, A., and Hanlon, C. R. (1950). The surgical treatment of complete transposition of the aorta and the pulmonary artery. Surg. Gynec. Obstet., 90, 1. 
Campbell, M., and Suzman, S. (1951). Transposition of the aorta and pulmonary artery. Circulation, 4, 329.

Coleman, E. N. (1965). Serious congenital heart disease in infancy. Brit. Heart f., 27, 42.

Cornell, W. P., Maxwell, R. E., Haller, J. A., and Sabiston, D. C. (1965). Results of the Blalock-Hanlon operation in 90 patients with transposition of the great vessels. 7. thorac. cardiovasc. Surg., 52, 525.

Hamilton, S. D., Bartley, T. D., Miller, R. H., Schiebler, G. L., and Marriott, H. J. L. (1968). Disturbances in atrial rhythm and conduction following the surgical creation of an atrial septal defect by the Blalock-Hanlon technique. Circulation, 38, 73.

Keith, J. D., Rowe, R. D., and Vlad, P. (1967). Heart Disease in Infancy and Childhood, 2nd ed. Macmillan, New York.

Mustard, W. T. (1964). Successful two-stage correction of transposition of the great vessels. Surgery, 55, 469.

-, Keon, W. J., and Trusler, G. A. (1968). Transposition of the great arteries and transposition of the lesser veins.
I. Transposition of the great arteries. Progr. cardiovasc. Dis., 11, 133.

Rashkind, W. J., and Miller, W. W. (1966). Creation of an atrial septal defect without thoracotomy: a palliative approach to complete transposition of the great arteries. f. Amer. med. Ass., 196, 991.

- and - (1968). Transposition of the great arteries. Results of palliation by balloon atroseptostomy in thirty-one infants. Circulation, 38, 453.

Shaher, R. M., and Kidd, L. (1966). Hemodynamics of complete transposition of the great vessels before and after the creation of an atrial septal defect. Circulation, 33, Suppl. 1, p. 3.

Singh, S. P., Astley, R., and Parsons, C. G. (1968). Haemodynamic effects of balloon septostomy in tricuspid atresia. Brit. med. F., 1, 225.

Tynan, M. J. (1968). Balloon atrial septostomy. Arch. Dis. Childh., 43, 744.

Watson, H., and Rashkind, W. J. (1967). Creation of atrial septal defects by balloon catheter in babies with transposition of the great arteries. Lancet, 1, 403. 